\title{
FESTA NO CERRADO
}

\author{
Rosselvelt José Santos*
}

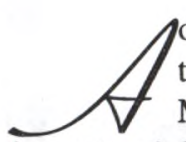
estudarmos as festas características do cerrado de Iraí de Minas-MG, fizemos algumas incursões à história do lugar e descobrimos reduções, adaptações e misturas culturais entre produtores mineiros e migrantes gaúchos nos encontros, nas celebrações e nas festividades da comunidade. Essa situação é vivida por esses produtores a partir dos anos 80 , como decorrência das estratégias do governo militar em reocupar e redefinir os cerrados como áreas especializadas na produção de cereais para os mercados mundiais.

A modernização da agricultura em Iraí de Minas, iniciada em 1980, é parte das estratégias de implantação do projeto binacional entre Brasil e Japão - "JICAPRODECER I" (Japan International Cooperation Agency ou Programa para o Desenvolvimento do Cerrado). Esse projeto introduziu no cerrado mineiro altíssima tecnologia e foi objetivado através da produção de cereais em grandes e médias fazendas em três núcleos-colônias nas regiões do Triângulo Mineiro e Alto Paranaíba.

Em Iraí de Minas, no Triângulo Mineiro, esse projeto promoveu a expansão das grandes lavouras de milho, sorgo e soja. Gerou infra-estrutura em transporte para viabilizar as exportações de tais produtos.

A expansão das grandes lavouras no município de Iraí de Minas, contou ainda com a migração de produtores camponeses cooperativados do Rio Grande do Sul. Os produtores que migraram quando da implantação do projeto foram os filhos dos camponeses que diante da impossibilidade de dividir a pequena propriedade familiar, viram na migração para o cerrado possibilidades de acesso a terra e continuarem reproduzindo-se ou mantendo-se como produtores rurais.

Assim, antes do projeto e da migração de camponeses gaúchos, em Iraí de Minas, os fazendeiros criavam gado extensivamente e secundariamente, as roças de subsistência eram produzidas por agricultores e meeiros.

"O povo todo criava gado... alguns muito e outros menos... Porque a criação dependia da quantidade de terra de cultura (de maior fertilidade) de meeiros que cada fazendeiro podia ter na propriedade. Também tinha aqueles que plantavam roças de milho, feijão, mandioca e criavam algumas vaquinhas, porcos e galinhas...". (Produtor mineiro) $)^{L}$

Considerando a sumária condição das atividades econômicas dos produtores, a ocupação das terras aconteceu a partir das características do solo. Em Iraí de Minas, os fazendeiros, assim como os agricultores, preferiram as terras dobradas onde os solos eram de maior fertilidade e abandonaram as áreas de chapadas.

Nas terras de média fertilidade predominavam as roças de milho, feijão e mandioca. Geralmente, essas terras eram instrumentos de negociações e acordos entre os fazendeiros, agricultores e meeiros. Por último, as terras de campo aberto ou de chapadas, de pouca fertilidade, representavam para os fazendeiros um recurso para colocar o gado de junho a setembro, período em que o cerrado seca, e essas áreas constituíam-se em opções de pastagens.

Nessa condição de produtores sumários, as queimadas eram técnicas utilizadas na limpeza dos pastos e implicavam negociações, acordos no estabelecimento de datas para realização de tais serviços em comunidade.

“...limpar o pasto, assim com fogo, tinha que ser feito com a participação dos vizinhos, porque eles tinham que fazer os aceros, tinha que protegê do fogo as áreas que eles não queriam

\section{queimar". (Produtor mineiro $)^{2}$}

Fazer a limpeza das áreas da propriedade envolvia a participação da comunidade. Concessões de parcelas de terra e até mesmo a venda de lotes dos fazendeiros aos agricultores eram realizadas sob negociações e acordos envolvendo trocas de serviços. Nas festas, sobretudo religiosas, os acordos, as negociações, eram celadas e reforçadas entre produtores. Desse modo, as festas aparecem como sustentação moral e espiritual dessa estrutura sócio-econômica.

"As festas sempre eram para reuniro povo, para a gente se visitá, se ajudá e também para rezar, para pedir proteção, para pagar e fazer votos aos santos e dar valor para os vizinhos...". (Produtor mineiro) $^{3}$

As iniciativas de reprodução e fortalecimento dos costumes como confiança mútua, credibilidade, inclusive de retribuir qualquer tipo de ajuda eram realizadas nas festas religiosas.

“Nossa! Antigamente os padres pregavam muito a ajuda entre os vizinhos, era só um sabê que o vizinho estava em dificuldade, assim doente que o pessoal se reunia e logo fazia uma traição, (reunião entre vizinhos para limpar um pasto, uma roça de surpresa...) Porque o povo sempre soube que sozinho ninguém dava conta de produzir." (Produtor mineiro) ${ }^{4}$

A comunidade organizada tinha a sua estrutura social constituída por fazendeiros, agricultores e meeiros. O entrelaçamento entre produtores advinha das suas condições sumárias de produção, da religiosidade e da consciência de que individualmente não lhes era garantida a reprodução das suas parcelas. Isto gerava iniciativas no interior da comunidade, que tornaram a ajuda mútua uma instituição que 
ampliava a credibilidade entre os produtores. A Igreja Católica, como promotora das festas, ampliava o seu poder e dividia esses ganhos políticos com os fazendeiros.

"Durante a festa de Nossa Senhora, Santa Terezinha e Santa Lúcia o povo fazia nove novena durante nove noites. $O$ povo vinha $e$ voltava das casas onde estavam as Santas todas as noites, durante a lua cheia. $O$ povo fazia tudo isso porque acreditava nos vizinhos, nas santas e nos fazendeiros... O povo tinha fé nos pedidos, nas confianças depositadas entre as pessoas. No dia da

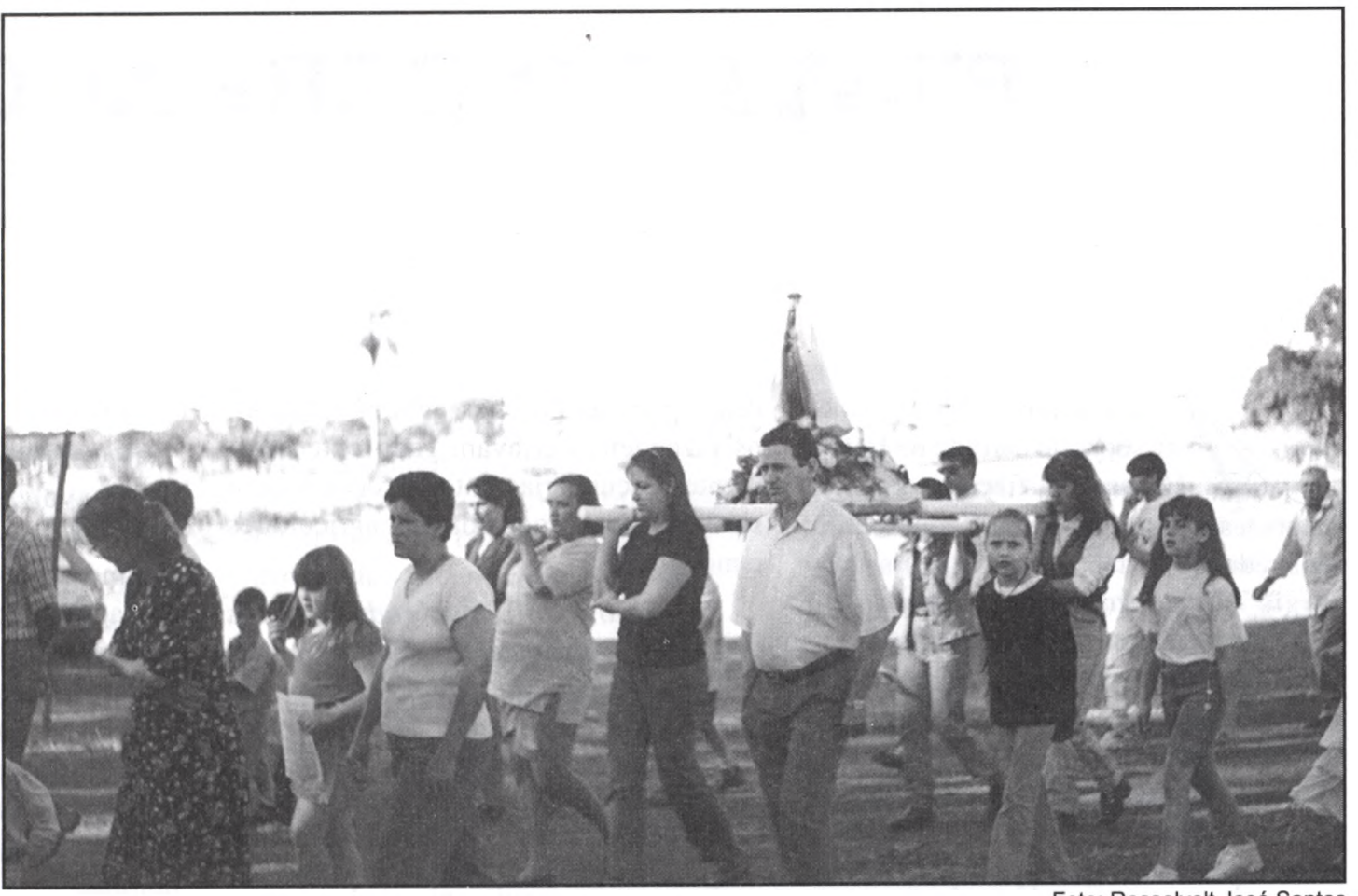
festa fazia um sorteio. Retirava um papel e decidia o próximo festeiro. $\mathrm{Na}$ casa do festeiro dava-se o almoço. $\mathrm{Na}$ casa do festeiro, o povo rezava, dançava e tinha muita comida...". (Produtor mineiro) ${ }^{5}$

As festas representavam encontros, celebrações de divindades, acordos no plantio, na colheita e na pecuária. Portanto, os produtores mineiros agiam organizando seus próprios tempos; mesmo com a mediação mais ou menos determinante de instituições como a Igreja Católica, foram sendo tecidas tramas profundas que aparecem depois como modo de ser das pessoas. A estabilidade de tais situações deriva sobretudo da posse e/ou propriedade de meios de vida, como neste caso, de todos os elementos conscernentes à propriedade territorial, nas formas como se inseria e suportava a reprodução social da comunidade.

As grande lavouras para exportação, fomentadas por acordo binacional entre Japão e Brasil na produção de cereais, não criaram apenas paisagens homogêneas. $\mathrm{O}$ próprio colorido dessas lavouras dá a idéia de que todos os produtores produzem as mesmas culturas durante o ano todo, o que seria verdadeiro se no cerrado não estivessem também os produtores mineiros e a

sua produção de leite. Por isso, as paisagens criadas pelas grandes lavouras escondem histórias dos produtores mineiros e dos gaúchos oriundos do Rio Grande do Sul, das suas festas, como também das festas reinventadas com a expansão da soja.

Por trás das grandes lavouras estão também a migração de camponeses (na sua maioria gaúchos), instalação de Cooperativas e de agências bancárias, como do Banco do Brasil. Nessa reocupaçãoe revalorização do cerrado de Iraí de Minas, desenvolveu-se rápida desagregação do modo de vida vigente, criando rupturas nas relações, nas propriedades, na cultura e nas instituições, tanto dos produtores mineiros, quanto dos produtores vindos do Sul do país.

\section{AS FESTAS ANTES DO "JICA- PRODECER 1"}

Conversando com os produtores mineiros e gaúchos, descobrimos as festas que aconteciam no Sul e em Iraí de Minas. Elas envolviam comunitariamente os produtores na sua criação, eram marcadas por momentos de solidariedade e de reafirmação de acordos. A festa era criação absolutamente importante para a reprodução da comunidade, tanto no Sul como no cerrado.

No cerrado tinha-se festa quase que todos os meses. Esse calendário envolvia a comunidade em rezas, celebrações e encontros entre vizinhos. No entanto, as festas de maior expressão na comunidade eram aquelas que envolviam acordos entre vizinhos, renovação da fé nas divindades católicas, nos plantios e nas colheitas. Desse modo, a folia de reis de 5 a 20 de janeiro marcava os votos em fazer as festas durante o ano todo. De 9 a 18 de fevereiro as festas de Nossa Senhora da Aparecida e de São Judas Tadeu marcavam o início das novenas nas casas dos produtores.

$\mathrm{Na}$ última semana de maio eram realizadas várias festas religiosas (Sagrado Coração de Jesus, Nossa Senhora do Rosário, São Tarcísio e festa do Divino com cavalhada). O objetivo era a preparação para a colheita das roças de milho e pedidos de proteção para o gado. Já nas festas Juninas (São João, São Pedro, Santo Antônio) comemorava-se a colheita do milho.

Em 29 de setembro, com a chegada das primeiras chuvas, com a necessidade de novos mutirões entre vizinhos, iniciavamse as novenas à Santa Terezinha e Santa Lúcia. No final de outubro a festa da Nossa Senhora da Cabeça renovava as esperanças em boas safras. Para os meses de novembro e dezembro as pessoas faziam 
poucas festas, havia em família intensa preparação para o Natal.

No Sul a condição de suinocultores cooperativados à Cooperativa COSUEL tinha reduzido bastante as festas em comunidade, pois o ritmo de trabalho determinado pelas imposições de mercado havia reduzido bastante o tempo dos agricultores para realizarem várias festas durante o ano. $\mathrm{Na}$ verdade, as imposições sociais lhes permitiam encontros de finais de semana na sede da comunidade. Assim, os encontros nas missas dominicais e as festividades realizadas em comunidades marcavam nos gaúchos momentos de jogos, celebrações e comemorações, principalmente nas festas religiosas, da cooperativa e entre familiares.

"No Rio Grande, tinha no dia 2 de fevereiro a festa da Nossa Senhora dos Navegantes, era uma festa dos tempos que se transportava tudo pelos rios. No dia 20 de março a festa era da Cooperativa. Em 16 de agosto a festa de São Roque... era da igreja, era para pedir proteção dos animais. Em setembro comemorava a Semana Farroupilha. Em outubro era a festa do laçador". (Produtor gaúcho) ${ }^{6}$

Produzindo confiança mútua entre os seus membros, as festas no cerrado e no Sul criavam identidade e, de certo modo, promoviam equilíbrios no processo de produção da vida das famílias e ajudavam no enfrentamento das incertezas e dos medos em relação à natureza. Equilíbrios materiais e não materiais, talvez traduzidos por ajuda/cooperação troca simples.

As festas, principalmente religiosas, eram responsáveis pela organização da comunidade, das famílias, pela consciência moral, política e por uma certa disciplina de seus membros na relação com a natureza e entre os homens.

Para envolver a comunidade, as festas eram grandiosas. Chegavam a durar mais de uma semana, celebrando padroeiros. As festas, assim como a reprodução das pessoas, estavam relacionadas aos ciclos da natureza. Enfim, elas expressavam um modo de ser, integravam os momentos da vida e indicavam também determinações institucionais, como da Igreja Católica.

A Igreja Católica, antes das grandes lavouras, institucionalizara as festas em Iraí de Minas de forma a seguir um calendário obedecendo ao ciclo da natureza do cerrado.

A acumulação política da Igreja Católica, a partir do calendário das festas, traduzia-se na forma como essa instituição milenar organizava a vida e as relações comunitárias dos produtores. A julgar pelo calendário das festas, a Igreja concentra saberes do ciclo da natureza, da comunidade em geral e, porque não dizer, de cada um de seus membros, assim como da riqueza produzida. Isto lhe permitia atuar nos casos particulares (relações pessoais e/ou institucionais), com conhecimento profundo da natureza, da comunidade e dos homens.

A festa abrigava dimensões de tempo. Tinha duração. Tinha o antes, o durante e o depois. Na condição de produtores simples, a centralidade da festa, manifestando-se como direção e sentido de atos, relações, decisões em suma, de práticas, de políticas, deriva do fato de que a comunidade dos mineiros administrava seu tempo. Faziam-no, conforme prescrições do mundo ao qual pertenciam, guardando uma certa institucionalidade, seja religiosa, seja estatal; mas a comunidade, enquanto tal, era dona do seu tempo. O tempo era presente-prático e disto derivava a centralidade da festa.

Isso tudo teve seu momento e deixou marcas profundas nos produtores e na comunidade. No entanto, foi sendo alterado na medida em que a infra-estrutura produzida pelo projeto viabiliza as rodovias, implantação de bancos, cooperativas, sindicatos, postos de recebimento de leite. Viabiliza também associações de produtores, sindicatos, escolas e laticínios, ampliando as possibilidades desse homem multiplicar as relações com o mundo. $\mathrm{O}$ modo de vida, as relações de produção e a própria produção vão então sofrendo as imposições decorrentes das transformações advindas da condição de produtores de leite para grandes laticínios, no caso dos mineiros, e de grandes produtores de cereais, no caso dos gaúchos.

Com ampliação das grandes lavouras e da produção de leite, resta na lembrança e na memória das populações migrantes e remanescentes do cerrado, fragmentos das relações ritmadas pelo ciclo natural do cerrado e das suas comunidades.

“Antigamente no Iraí era festa para tudo, era dos santos, da colheita, do gado...". (Produtor mineiro)

"No Rio Grande, na nossa comunidade, era sempre festão, era churrasco de 200 leitões". (Produtor gaúcho) ${ }^{7}$

Além das lembranças, é possível, entre os produtores mineiros e gaúchos, verificar resíduos de valores morais, éticos, sabedorias, momentos de criatividade e, fundamentalmente, estratégias nas relações sociais de produção que são reproduzidas nas festas que se adaptam e se inventam no processo de produção das grandes lavouras e de leite para grandes laticínios.

\section{REDEFINIÇÃO E REINVENÇÃO DAS FESTAS}

A rigor, as festas dos mineiros e dos gaúchos foram sendo instituídas pela Igreja Católica. Atualmente, é possível entre gaúchos e mineiros esforços em redefinir e reinventar as festas. Em relação aos mineiros, entre alguns vizinhos da zona rural, manter vivas algumas das festas de tradição folclórico-religiosa, implica em buscar na cidade o festeiro e os membros da comunidade ausentes.

\section{"Essa festa do Divino é feita pelo povo que vem de toda a parte, ofesteiro e a maioria do povo vem da cidade, por- que a roça tá cada vez mais vazia de gente, assim trazer o povo é uma ma- neira de manter as nossas festas...". (Produtor mineiro) $^{8}$}

Desse passado das festas camponesas algo subsiste, a religiosidade e a criatividade camponesa. Esse passado se inscreve e reage na vida desses produtores como tentativa de interpretar, manter e adaptar as festas camponesas às transformações do modo de vida.

"Na época que as festas eram animadas os padres tinham poder. A religião, os dias dos santos eram respeitados. Hoje não dá para respeitar todos os dias dos santos... Então para continuar fazendo as festas tem que ser nos finais de semanas, reunir vários santos numa só festa e buscar apoio do padre, trazer o povo da cidade e fazer o que der, o que não der para fazer a gente deixa de lado, porque a gente 
não dá conta sozinho de tudo". (Produtor mineiro) ${ }^{9}$

Bastante reduzidas as festas camponesas, isto não quer dizer que estejam mortas, mas são muito poucas, comparadas com as festas que havia quando a comunidade existia estruturada na pecuária extensiva, ao redor das divindades, da solidariedade e da Igreja Católica.

Portanto, atualmente, a consciência dos produtores é de que as festas são diferentes, perderam parte dos sentimentos, das identidades religiosas e dos significados para a vida em comunidade.

"As festas eram muitas..., muita reunião, muita gente fazendo as festas... porque eram importantes para a vida... $O$ povo dava o que podia para fazer as festas". (Produtor mineiro) $)^{10}$

"Nas festas do Sul tinha muito jogo, muita rifa, muita gente. Tinha amizade, tinha vontade, tinha doação, era uma felicidade". (Produtor gaúcho)"

Essas festas, como eram não existem mais. No entanto, existem redefinidas. Sua sobrevivência tem que ser entendida como esforço, como estratégia, como redefinição, como invenção que procura reunir diferentes produtores, várias divindades e dar outros sentidos à sua manutenção.

"A festa da cavalhada, do Divino, da Folia de Reis era de muita importância para a nossa precisão... Para nós hoje, tem o sentido da reunião, da reza, da amizade e de algumas coisas mais". (Produtor mineiro) $^{12}$

A festa da cavalhada, do Divino, da Folia de Reis, entre os produtores mineiros, aparecem como paródias das festas camponesas de antigamente. Festas que, apesar de reduzidas, reúnem pessoas do campo e da cidade, os mineiros e os gaúchos. A reunião aparentemente não cria identidades entre essas pessoas; então por que se aproximam? Na nossa pesquisa descobrimos outras necessidades que já não são totalmente satisfeitas pelo consumo dos shows, dos espetáculos produzidos como mercadoria em outras festas recentemente inventadas como a da soja e do trigo.

"A festa do trigo e da soja é muito boa, é grande, agitada, mas, ela não tem tudo o que as outras festas tem... Fal- ta uma coisa assim de reunião, de fé, de encontro, de amizade". (Produtor mineiro) $)^{13}$

Nessas necessidades de aproximações, cujo objetivo não é promover resistências às imposições econômicas, descobrimos elaborações de jogos, de jantares e de expressões culturais resgatadas e inventadas junto aos produtores mineiros e gaúchos.

"Toda sexta-feira tem galinhada, no final de maio nós fizemos a festa da cavalhada, juntamos vários santos e criamos o desfile dos cavaleiros, provas de argolas, de cartuchos e fizemos a procissão, isto reúne o povo todo". (Produtor mineiro) $^{14}$

As aproximações revelam manifestações culturais que indicam esforços em gerar sentidos às festas, e de certa forma, superar as perdas que esses grupos de produtores acumularam na reocupação $\mathrm{e}$ redefinição do cerrado.

$\mathrm{Na}$ verdade, descobrem-se nas festas aproximações que não recuperam as festas nem dos produtores mineiros e muito menos dos gaúchos. Vivem-se nessas aproximações esforços para recriar as festas e até mesmo inventar novas festas, novos costumes, encontros e sentidos dando significações a suas práticas. Os esforços, tanto dos produtores mineiros como dos gaúchos, conseguem inventar novos encontros que nem sempre têm fundamentação na história desses produtores.

“...sobre a festa da cavalhada eu só acho bonita, não entendo muita coisa, mais é uma oportunidade para a gente se encontrar, conversar, trazer a família...". (Produtor gaúcho) ${ }^{15}$

Quaisquer que sejam os atributos e as determinações do cerrado reocupado e redefinido, têm-se criado alguns problemas às manifestações humanas, mas também soluções. Como problema tem-se a falta de tempo, de espaço e de sentido às adaptações das festas. Portanto, as festas reaparecem e podem permanecer se começarem a serem aceitas como adaptações e fundadoras de novos sentidos, ou seja, como possibilidade de satisfazer o lazer, $o$ lúdico, enfim, essas necessidades que são satisfeitas e insatisfeitas pelo consumo do espetáculo como mercadorias.

Nesse processo vai-se produzindo algo para se colocar no lugar das festas camponesas. Mas, o dramático é que as humanidades antigas do cerrado e do camponês gaúcho não têm mais lugar e criam-se outras humanidades, manifestações que ocupam o lugar das festas camponesas.

As festas camponesas sofrem reduções nas suas tentativas de recuperação; promovem aproximações entre produtores diferentes. Os objetivos que marcavam a festa, em momentos onde a comunidade era importante para se enfrentar as imposições de ordem natural, mudaram, em função de que também as relações com a natureza foram profundamente alteradas. Portanto, esse homem também mudou, assim como suas manifestações de criatividades, de reação, também sofreram reduções, superações, a partir das transformações da produção.

Obviamente, as festas de antigamente não têm razão de ser tais como eram concebidas e realizadas pelas comunidades camponesas, tanto no Sul, como no cerrado. Mas, a necessidade da festa ainda persiste entre esses produtores. Na verdade, a festa, mesmo miniaturizada, revela traços da cultura camponesa e da religiosidade desses homens. Mostra a necessidade de depositarem nas divindades algumas mistificações à satisfação das imposições sociais, que estão imbricadas na condição de produtores tecnificados de cereais ou de leite.

Nesse momento cabe questionar sobre o que sobrou da cultura camponesa. A festa miniaturizada, parodiada, transformada em vários sentidos, cujos intérpretes são, sem dúvida, os produtores mineiros e gaúchos. Nessa recriação não é raro reivindicálas como espetáculo.

“... A festa da cavalhada tinha que ter mais coisas. Ela é bonita, mas eu acho que só os cavalos enfeitados, as provas de argolas e de cartuchos é pouco. Acho que tinha que melhorar, trazer umas coisas dos rodeios...". (Produtor gaúcho) ${ }^{16}$

Para interpretarmos as razões das festas, precisamos entender que elas foram reinventadas a partir das condições sociais de produção, criadas no cerrado pelo projeto "JICA-PRODECER 1". A partir da reocupação e da redefinição dessas terras, os produtores, sobretudo os gaúchos, produzem sob determinações de altíssima 


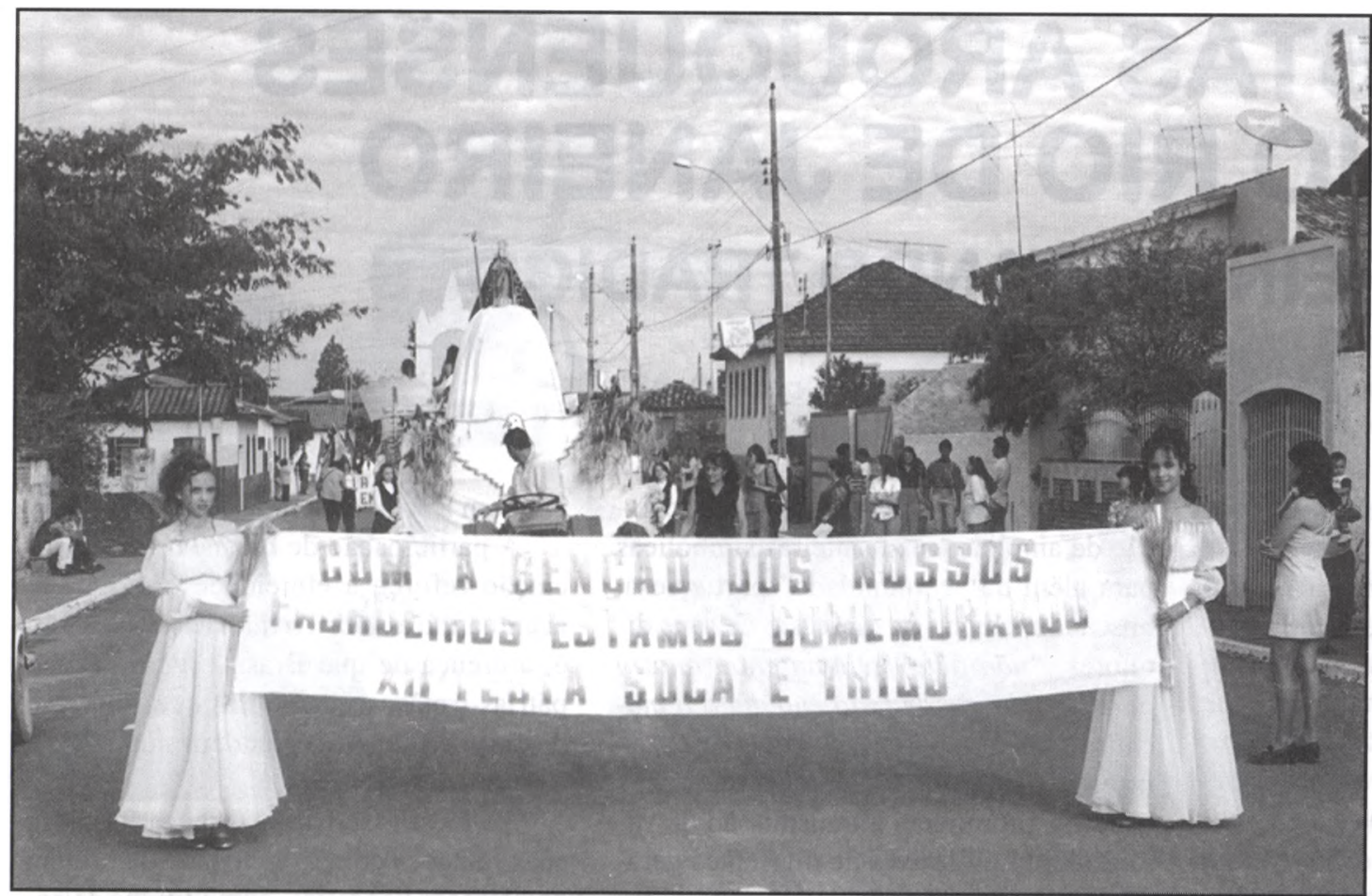

tece independente das hierarquias constituídas pelos domínios de instituições, como a Igreja Católica, esses homens expressam e ampliam as suas condições de estabelecer relações com o mundo. Sendo a sua existência relativa à natureza das atividades, eles vivem, na reocupação dos cerrados, a eliminação das necessidades de acordos comunitários, do trabalho comunitário, dos liames de solidariedade no trabalho. De modo que, o movimento da modernidade em todos os domínios conduz à dessacralização (Marx, 1988). Assim, a festa continua, mas há substituição da festa pelo espetáculo. A festa, como espetáculo, ten-

tecnologia. Portanto, as tradições misturadas e adaptadas às crenças nas divindades redefinidas, em função das conquistas tecnológicas, são manifestações de transformações das relações dos homens com a natureza e de suas novas carências.

Nessa condição das conquistas tecnológicas a festa do trigo e da soja é uma invenção que mistura aspectos das festas camponesas e introduz o espetáculo. Sendo de iniciativa do poder público e da cooperativa, ela introduz uma sociabilidade nova entre os produtores mineiros e gaúchos. Pois gaúchos e muito menos mineiros não eram, até 1980 , produtores especializados na soja e no trigo.

A festa dos principais produtos das grandes lavouras no cerrado contém invenções criadas na perspectiva de consolidar a produção sob altíssima tecnologia. A primeira invenção, a qual acontece na abertura da "festa do trigo e da soja" é a escolha da rainha, seguida de show e baile na praça da matriz. A escolha da rainha é a expressão de estratégia para reunir os mineiros e os gaúchos. Entre as concorrentes da festa de 1997, duas moças eram mineiras e uma gaúcha.

Outras invenções são os esportes de massa, como o campeonato de futebol, concurso de violeiros regionais, desfiles de escolas, firmas, máquinas agrícolas e cooperativas.

Também é celebrada a Santa Missa. Os padroeiros aparecem na missa como sendo do lugar, dos mineiros-gaúchos ou dos gaúchos-mineiros. Mas, o marcante nessas invenções são as misturas culturais, os shows e os bailes gigantescos, que se realizam durante os quatro dias de festividades e espetáculos.

Não é por acaso que a festa se torna mais ou menos importante entre os produtores a partir das duplas sertanejas ou bandas de rock que animam os shows e os bailes cada vez mais espetaculares na praça da matriz. Estabelecer a realização de shows, bailes grandiosos em praça pública parece ser a caracterização de uma necessidade das pessoas já que nas outras festas em comunidade não é possível produzir esse tipo de espetáculo que vem pronto de fora mas, a festa como coletividade. Em outros termos, a festa existe para/em coletividade. A festa reúne os habitantes, algumas coisas vêm de dentro da comunidade, outras vêm de fora; a síntese é uma mistura de cultura que já é particular do próprio lugar (um pouco dos gaúchos, um pouco dos mineiros) e produto para o consumo, o espetáculo (de fora).

Como a "festa do trigo e da soja" acon- de à autonomia, para ter uma existência em si mesmo em função de uma necessidade nova, a de propiciar atos práticos entre os indivíduos. Enfim, para criar oportunidades de reconhecimento de produtores subordinados às estratégias de reprodução do capital agroindustrial, as quais não são suas.

* Rosselvelt José Santos é Prof. do Dpto. de Geografia da UF de Uberlândia/MG.

\section{NOTAS}

1-16 - Anotações de trabalho de campo realizado no período de 1994-97.

\section{BIBLIOGRAFIA}

\section{GUY, Debord}

(1997) A Sociedade do Espetáculo. Rio de Janeiro, Contraponto.

LEFEBVRE, Henri

(1967) El Marxismo Sin Mitos. Buenos Aires. A. Pena Lillo.

HOBSBAWM, E.

(1984) A Invenção das Tradições. Rio de Janeiro, Paz e Terra.

MARX, Karl

(1984) Manuscritos Economia y Filosofia. Madri, Alianza Editorial.

MARX, Karl

(1988) O Manifesto do Partido Comunista. São Paulo, Global.

MARTINS, José de Souza

(1986) Não Há Terra para Plantar neste Verão. Petrópolis, Vozes. 